\section{The awareness level of orthodontic treatment among early adolescents (a survey among students of 111 public Junior High School, Jakarta)}

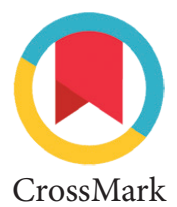

Khuzaima Adyasti, Dwita Pratiwi, ${ }^{*}$ Erwin Siregar

\title{
Abstract
}

Objective: The purpose of this study is to describe the distribution of the awareness level of orthodontic treatment in students of 111 Public Junior High School, Jakarta and to compare it between male and female subjects.

Material and Methods: A cross-sectional study was held to 107 students aged 12-14 years old in 111 Public Junior High School, Jakarta. This study was analyzed using univariate and Mann-Whitney analysis with a $95 \%$ confidence level.

Results: The awareness level of most students is moderate (45.8\%), followed by high level of awareness (33.6\%) and low level of awareness (20.6\%). The median and range of the total score in female subjects are 28 (14-34), while in male subjects, the median and range are 24 (13-34). There is significant difference of orthodontic treatment awareness between male and female subjects $(P=0.028)$.

Conclusion: The awareness level of orthodontic treatment in early adolescents is moderate. Female subjects have higher level of awareness about orthodontic treatment than male subjects.
Department of Orthodontics, Faculty of Dentistry, Universitas Indonesia, Jakarta, Indonesia
*Correspondence to: Dwita Pratiwi, Department of Orthodontics, Faculty of Dentistry, Universitas Indonesia, Jakarta, Indonesia dwitapratiwi14@gmail.com

Received: 19 0ctober 2020 Revised: 18 November 2020 Accepted: 3 February 2021 Available Online: 1 April 2021

Keywords: Awareness of orthodontic treatment, Early adolescents

Cite this Article: Adyasti K, Pratiwi D, Siregar E. 2021. The awareness level of orthodontic treatment among early adolescents (a survey among students of 111 public Junior High School, Jakarta). Journal of Dentomaxillofacial Science 6(1): 5-9. D0I: 10.15562/jdmfs.v6i1.1112

\section{Introduction}

Malocclusion is defined as the deviation from normal occlusion which process has begun from the early period of human's growth. This condition is affected by genetic factors, environmental factors, or the combination of both factors. Despite not being a pathological condition, malocclusion has some negative effects towards the quality of life, particularly in health and psychosocial aspects. ${ }^{1}$ Some of the psychosocial effects are lack of selfesteem and body image dissatisfaction for those whose malocclusion affects their facial appearance, which possibly cause peer discrimination..$^{2-4}$ In order to overcome these issues, one can get benefited from orthodontic treatment.

Generally, most cases of malocclusion were treated at the early permanent dentition phase, which around the age of adolescence. According to Sanders, adolescent years can be divided into early adolescence (ages 12-14 years), middle adolescence (ages 15-17 years), and late adolescence (ages 18-21 years). During the early phase, adolescents starts to worry about how they appear to others. ${ }^{5}$ They view their appearance as an important factor to build their self-esteem and tend to feel dissatisfied when their looks did not reach the standard they hoped for. ${ }^{6}$ Jung reports that orthodontic treatment has improved the self-esteem in Hong Kong adolescents with malocclusion. ${ }^{7}$
Based on 2013 Indonesia Basic Health Research (RISKESDAS 2013), there are 14.5\% adolescents aged 12- 14 years old with crowded teeth and only $0.8 \%$ of adolescents had received orthodontic treatment in Indonesia. This gap shows that some factors are affecting their decision regarding seeking any orthodontic treatment. One of these factors is the awareness about the treatment itself. ${ }^{8}$ As stated by Bloom, awareness is the first step to adopt a new behavior. The research conducted by Essamet et al. ${ }^{9}$ found that awareness about orthodontic treatment potentially becomes the motivation to start and comply with the whole treatment. ${ }^{9}$

Some previous researches have been conducted to analyze the level of awareness about orthodontic treatment in adolescents, but as far as it is known, there has not been any research regarding orthodontic treatment awareness among early adolescents in Jakarta.9-11 Therefore, this study aims to analyze the level of awareness about orthodontic treatment among early adolescents in Jakarta. The null hypothesis is that there is no significant difference between the awareness level of female and male subjects. ${ }^{12}$

\section{Material and Methods}

A cross-sectional study was conducted at 111 Public Junior High School, Jakarta on December 2019. A 
total of 107 students were selected as subjects which number determined by the minimum sample size count using categorical descriptive formula. The inclusion criteria of the subjects are; active students of 111 Public Junior High School when the data was obtained, aged 12-14 years old and has given their consent of being the research's subject. Students who already received orthodontic treatment or having family members with orthodontic appliances were excluded from this research. The ethical approval of this research was obtained from Dentistry Research Ethical Committee, Faculty of Dentistry, Universitas Indonesia (No. 133/Ethical Approval/FKGUI/XII/2019).

A questionnaire adapted from Shekar et al. ${ }^{10}$ that assess knowledge, attitude, and practice regarding orthodontic treatment is used in this research. ${ }^{10}$ The original questionnaire was constructed in English, later translated into Bahasa Indonesia and modified to conform with Indonesian early adolescents' understanding. After the translation process, the preliminary questionnaire with 23 close-ended questions is distributed to 30 respondents that were not included as subjects of this research, which result was being used to assess the questionnaire's validity and reliability.

The validity and reliability of the questionnaire were analyzed using Special Package for Social Sciences (SPSS) 25 software. Each question's validity was tested with bivariate correlation (person) test with significance level of $5 \%$ and $r=0.3610$, which leaves 20 valid questions. The reliability of the questionnaire was acceptable with cronbach's a $=0.864$. The final questionnaire later handed and filled by the subjects after obtaining their written consent. Following the completion of the questionnaire, they were given information's regarding malocclusion and orthodontic treatment.

In this questionnaire, each question provided has "Yes", "No", and "Don't know" answer choice. The scoring value of the answers are based on Likert scale, with "Yes" $=2$ points, "No" $=1$ points, and

\section{Table 1 Sociodemographic characteristics distribution of the} subjects

\begin{tabular}{ll}
\hline Sociodemographic Characteristics & $\mathbf{N}(\%)$ \\
\hline Gender & $53(49.5)$ \\
$\quad$ Male & $54(50.5)$ \\
Female & \\
Age & $35(32.7)$ \\
12 years old & $36(33.6)$ \\
13 years old & $36(33.6)$ \\
\hline 14 years old & \\
\hline
\end{tabular}

"Don't know" $=0$ points. Maximum total score is 40 , which represents high awareness level. The data obtained were processed and analyzed using SPSS 25 software with univariate and Mann-Whitney analysis.

\section{Results}

There are 107 participants that fulfilled the inclusion and exclusion criteria, with 53 male subjects and 54 female subjects. 35 subjects are 12 years old, 36 subjects aged 13 years old, and 36 subjects are 14 years old. The distribution of sociodemographic characteristics is stated in table 1 and the distribution of the answers is stated in table 2.

The awareness level of orthodontic treatment then categorized into high, moderate, and low level of awareness using cut-off points determined by Receiving Operating Characteristics (ROC) curve between the subject's response regarding the fourteenth question, "Have you ever heard about orthodontic treatment?" and the total score of the questionnaire. The cut-off point for low and high level of awareness is 20.5 and 28.5, respectively.

In conclusion, subjects with total score equal to or higher than 28.5 categorized into high level of awareness. Subjects with total score ranged from 20.5-28.5 is categorized into moderate level of awareness, and total score of equal to or lower than 20.5 is categorized as having low orthodontic treatment awareness. The distribution of orthodontic treatment awareness level is shown in table 3.

Most of the subjects (45.8\%) have moderate level of awareness, both in male and female subjects. The median and range of the total score in male subjects are 24 (13-34), while in female subjects, the median and range are 28 (14-24). The data later subjected to Mann-Whitney test with a 95\% confidence level to compare the level of awareness between male and female subjects, which shows a significant difference $(P=0.028)$ as stated in table 4 .

\section{Discussion}

The awareness about orthodontic treatment is influenced by objective and subjective factors. ${ }^{13}$ Objectively, it is affected by the severity of malocclusion. One of the grading systems that commonly used is Index of Orthodontic Treatment (IOTN). On the other hand, various subjective factors that affects orthodontic treatment awareness are age, gender, level of education, and perception regarding the psychosocial effects of maloclussion. ${ }^{13}$ This research assessed the awareness level of orthodontic treatment based on subjective factors. Previous researches show conflicting results. Orthodontic 
Table 2 Distribution of subject's responses

\begin{tabular}{|c|c|c|c|c|}
\hline No & Question & $\begin{array}{l}\text { Yes } \\
\mathbf{N}(\%)\end{array}$ & $\begin{array}{l}\text { No } \\
\text { N(\%) }\end{array}$ & $\begin{array}{c}\text { Don't know } \\
N(\%)\end{array}$ \\
\hline 1 & Have you ever heard the term loose teeth? & $102(95.3)$ & $2(1.9)$ & $3(2.8)$ \\
\hline 2 & $\begin{array}{l}\text { Can the untidy teeth in children be passed down } \\
\text { from their parents? }\end{array}$ & $25(23.4)$ & $42(39.2)$ & $40(37.4)$ \\
\hline 3 & $\begin{array}{l}\text { In your opinion, can the condition of 'cameuh' in } \\
\text { children be inherited from the parents? }\end{array}$ & $10(9.3)$ & $4(3.7)$ & $93(86.9)$ \\
\hline 4 & $\begin{array}{l}\text { Do you think that thumb sucking can cause loose } \\
\text { teeth? }\end{array}$ & $27(25.2)$ & $40(37.4)$ & $40(37.4)$ \\
\hline 5 & $\begin{array}{l}\text { In your opinion, can the habit of sticking out } \\
\text { your tongue cause loose teeth? }\end{array}$ & $5(4.7)$ & $55(51.4)$ & $47(43.9)$ \\
\hline 6 & $\begin{array}{l}\text { In your opinion, can the habit of breathing } \\
\text { through the mouth cause untidy teeth? }\end{array}$ & $4(3.7)$ & $65(60.7)$ & $38(55.5)$ \\
\hline 7 & $\begin{array}{l}\text { In your opinion, does an untidy tooth } \\
\text { arrangement affect your appearance? }\end{array}$ & $85(79.4)$ & $13(12.1)$ & $9(8.4)$ \\
\hline 8 & $\begin{array}{l}\text { In your opinion, does an untidy tooth } \\
\text { arrangement affect your chewing ability? }\end{array}$ & $56(52.3)$ & $27(25.2)$ & $24(22.4)$ \\
\hline 9 & Do you think that untidy teeth can affect speech? & $45(42.5)$ & $33(30.8)$ & $29(27.1)$ \\
\hline 10 & $\begin{array}{l}\text { In your opinion, is a tidy dental checkup and care } \\
\text { important for children and adolescents? }\end{array}$ & $92(86)$ & $5(4.7)$ & $10(9.3)$ \\
\hline 11 & In your opinion, can an untidy tooth be repaired? & $102(95.3)$ & $1(0.9)$ & $4(3.8)$ \\
\hline 12 & Have you ever heard the term braces? & $107(100)$ & 0 & 0 \\
\hline 13 & Have you ever seen braces? & $106(99.1)$ & $1(0.9)$ & 0 \\
\hline 14 & $\begin{array}{l}\text { Have you ever heard of the term orthodontic } \\
\text { treatment? }\end{array}$ & $18(16.8)$ & $70(65.4)$ & $19(17.8)$ \\
\hline 15 & In your opinion, does braces take a long time? & $68(63.6)$ & $11(10.3)$ & $28(26.2)$ \\
\hline 16 & $\begin{array}{l}\text { Will you still want to receive braces once you } \\
\text { know the length of treatment? }\end{array}$ & $57(53.3)$ & $19(17.8)$ & $31(29)$ \\
\hline 17 & $\begin{array}{l}\text { If some of your teeth had to be removed to } \\
\text { improve the alignment of your teeth, would you } \\
\text { accept that? }\end{array}$ & $64(59.8)$ & $25(23.4)$ & $18(16.8)$ \\
\hline 18 & Do you know the side effects of braces treatment? & $22(20.6)$ & $48(44.9)$ & $37(34.6)$ \\
\hline 19 & Did you know that using braces will cause pain? & $66(61.7)$ & $14(13.1)$ & $27(25.2)$ \\
\hline 20 & $\begin{array}{l}\text { Will you still want to receive braces once you } \\
\text { know the possibility of pain? }\end{array}$ & $43(40.2)$ & $30(28)$ & $34(31.8)$ \\
\hline
\end{tabular}

Table 3 Distribution of orthodontic treatment awareness level

\begin{tabular}{lccc}
\hline Awareness level & $\begin{array}{c}\text { Male } \\
\mathbf{N}(\%)\end{array}$ & $\begin{array}{c}\text { Female } \\
\mathbf{N}(\%)\end{array}$ & $\begin{array}{c}\text { Total } \\
\mathbf{N}(\%)\end{array}$ \\
\hline High & $15(28.3)$ & $21(38.9)$ & $36(33.6)$ \\
Moderate & $22(41.5)$ & $27(50)$ & $49(45.8)$ \\
Low & $16(30.2)$ & $6(11.1)$ & $22(20.6)$ \\
\hline
\end{tabular}

Table 4 Mann-Whitney analysis for comparison between male and female subjects

\begin{tabular}{lcc}
\hline & Median (minimum-maximum) & P Value \\
\hline Male $(\mathrm{n}=53)$ & $24(13-34)$ & 0.028 \\
Female $(\mathrm{n}=54)$ & $28(14-34)$ & \\
\hline
\end{tabular}

treatment and female subjects has higher level of awareness. ${ }^{10}$ Contrary to this, Mane et al. found that male subjects have higher level of awareness. ${ }^{11}$

As stated by Bloom, human behavior consists of cognitive (knowledge), affective (attitude), and psychomotor (practice) domain, which points can be used to determine awareness. In order to assess orthodontic treatment awareness, the questionnaire used in this research consists of questions to evaluate knowledge and attitude regarding orthodontic treatment. The practice of orthodontic treatment was not being assessed because the chosen subjects do not have previous orthodontic experience.

Knowledge about orthodontic treatment was assessed through questions about common 
colloquialisms in Bahasa Indonesia related to malocclusion and orthodontic treatment, factors that caused malocclusion, effects of malocclusion, the term "orthodontic treatment", and the importance of orthodontic treatment. Most of the subjects appear to have relatively low knowledge regarding bad habits that can cause malocclusion, such as thumb sucking, tongue thrusting, and mouth breathing. This result shows an alignment with findings from Soni et al. ${ }^{14}$

Malocclusion is known to give rise to health and psychosocial issues, such as disturbance of mastication process, temporomandibular joint disorder, body image dissatisfaction, and lack of self-esteem. In this research, most subjects already realized the effect of malocclusion on facial appearance, consistent with reports from Imani et al. ${ }^{6}$ and Soni et al..$^{14}$ On the other hand, health issues related to malocclusion were less known by the subjects. Most of this study's subjects know that malocclusion can be fixed and already realized the importance of receiving orthodontic treatment for those with malocclusion.

Subject's attitude towards orthodontic treatment was assessed using questions regarding treatment duration, side effects of orthodontic treatment, and the willingness to receive an orthodontic treatment. The subjects mostly know about long orthodontic treatment duration. Only half of them agreed to receive an orthodontic treatment after knowing that fact, which shows the possible hesitation to start a treatment because of its duration. This result aligns with the report from Shekar et al. where most of their subjects refused an orthodontic treatment because of its duration. ${ }^{10}$

Other than the long treatment duration, orthodontic treatment also has its risks, such as pain, ulcerations, and discomfort. The majority of the subjects already know the risk of feeling pain when going through orthodontic treatment. Most of them chose not to receive the treatment after knowing such risks, contrary to findings from Costa et al. where adolescents' desire for having their teeth well-aligned overcomes the fear of facing its risks. ${ }^{15}$

Some malocclusion cases require tooth extraction. In this research, most subjects refused to have an orthodontic treatment if they have to lose their teeth due to extraction. Therefore, it is possible that even though the subjects have enough knowledge about malocclusion and orthodontic treatment, the fear towards its risks made them refuse to seek an orthodontic treatment. This study shows there are more subjects who fears their tooth being extracted compared to the risk of orthodontic pain, probably because the subjects did not have enough knowledge about the benefits and risks of extraction before orthodontic treatment. In any case that requires extraction, the orthodontist needs to explain their reasoning and discuss it with the patient. ${ }^{16}$

The result of this study shows moderate level of awareness about orthodontic treatment among early adolescents in 111 Public Junior High School, Jakarta. Female subjects significantly have higher mean total score than male subjects. This shows alignment with Jung. ${ }^{7}$ which states that malocclusion affects female adolescents' self-esteem more than males, making them more aware about their appearance. Shekar et al. ${ }^{10}$ and Essamet et al. ${ }^{9}$ also states that females tend to have higher level of awareness about orthodontic treatment and higher desire to have a good facial appearance. ${ }^{9,10}$ This may cause by female puberty that occurs 2 years earlier than male in average. According to Sanders, early puberty has been identified as a risk factor for poor body image on female adolescents. ${ }^{5}$

\section{Conclusion}

The level of awareness about orthodontic treatment among early adolescents in 111 Public Junior High School is moderate. The decision of not seeking an orthodontic treatment despite having good knowledge about it can be caused by some factors, such as its long duration, the fear of having their teeth extracted before treatment, and fear of pain. Female subjects are significantly more aware about orthodontic treatment than male subjects. In the future, it is suggested to have a further research about the relation between orthodontic treatment awareness and the objective orthodontic treatment need. Dentists can also provide informations about malocclusion and orthodontic treatment in social medias to reach the intended audiences.

\section{Acknowledgment}

Thank you for the support Department of Orthodontics, Faculty of Dentistry, Universitas Indonesia.

\section{Conflict of Interest}

The authors report no conflict of interest.

\section{References}

1. Chen M, Feng Z-C, Liu X, et al. Impact of malocclusion on oral-health related quality of life in young adults. Angle Orthod 2015;85: 986- 991.

2. Brizon VSC, Cortellazzi KL, Vazquez FL, et al. Individual and contextual factors associated with malocclusion in Brazilian children. Rev Saúde Pública 2013;47: 1- 11.

3. Baram D, Yang Y, Ren C, et al. Orthodontic treatmentneed and the psychosocial impact of malocclusion in 
12-year-old Hong Kong children. Sci World J 2019;12: 1-9.

4. Banu A, Șerban C, Pricop M, et al. Dental health between self-perception, clinical evaluation and body image dissatisfaction - a cross-sectional study in mixed dentition prepubertal children. BMC Oral Health 2018;18: 74.

5. Sanders RA. Adolescent psychosocial, social, and cognitive development. Pediatr Rev 2013;34: 354- 359.

6. Imani MM, Jalali A, Dinmohammadi M, et al. The effect of orthodontic intervention on mental health and body image. Maced J Med Sci 2018;6: 1132- 1137.

7. Jung M-H. Evaluation of the effects of malocclusion and orthodontic treatment on self-esteem in an adolescent population. Am J Orthod Dentofacial Orthop 2010;138: $160-166$.

8. Harish A, Sanjeev J, Khetal N, et al. Survey on awareness about orthodontic treatment in general population of Nagpur district. Int J Adv Res 2017;5: 500- 504.

9. Essamet M, Darout IA. Awareness and behavior related to orthodontic treatment among Jazan University students, Kingdom of Saudi Arabia. J Dent Oral Hyg 2016;8: 12- 17.

10. Shekar S, Chandrashekar B, Bhagyalakshmi A, et al. Knowledge, attitude and practices related to orthodontic treatment among college students in rural and urban areas of Mysore, India: a cross-sectional questionnaire study. Indian J Oral Health Res 2017;3: 9- 14.
11. Mane P, Patil S, Kadam K, et al. Evaluation of the awareness and knowledge of orthodontics and orthodontic treatment in patients visiting school of dental sciences, Karad. J Oral Res Rev 2018;10: 62- 67.

12. Oliveira MA, Bendo CB, Paiva SM, et al. Determining cutoff points for the dental fear survey. Sci World J 2015;2015: 17.

13. Li X, Tang Y, Huang X, et al. Factors influencing subjective orthodontic treatment need and culture-related differences among Chinese natives and foreign inhabitants. Int J Oral Sci 2010;2: 149- 157

14. Soni U, Baheti M, Dash S, et al. Knowledge and awareness of malocclusion among rural population in India. Asian Pac J Health Sci 2014;1: 329- 334.

15. Costa AA, Ferreira MC, Serra-Negra JM, et al. Impact of wearing fixed orthodontic appliances on oral healthrelated quality of life among Brazilian children. J Orthod 2011;38: 275- 281.

16. Pawinru AS. Angulation change of the third molar tooth in orthodontic treatment. J Dentomaxillofac Sci 2017;2: 32-36.

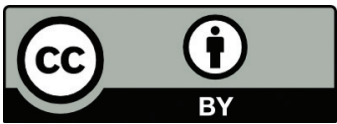

This work is licensed under a Creative Commons Attribution 